\title{
Educação em Direitos Humanos e para a Cidadania e a Formação Docente na Educação Infantil: Uma Revisão Sistemática da Literatura
}

\begin{abstract}
Ana Paula Ribeiro Nunes
Coordenadora Pedagógica - Ceitjto (2018). Especialista em Neuropsicopedagogia Censupeg (2017). Especialista em Psicopedagogia Clínica e Institucional pelo o Ibexp (2005). Graduada em Pedagogia - Unitins/Eadcon (2004). apribnes@hotmail.com

\section{Patricia Medina}

Doutora em Educação. Mestre em Administração de Sistemas Educacionais. Pedagoga e bacharel em Direito. Professora no curso de Pedagogia da UFT e do Mestrado Profissional Interdisciplinar em Prestações Jurisdicional e Direitos Humanos (PPPJDH) - Universidade Federal do Tocantins (UFT) e Tribunal de Justiça do Estado do Tocantins (TJ/TO) por meio da Escola Superior da Magistratura

Tocantinense (Esmat). patriciamedina@uft.edu.br
\end{abstract}

O presente artigo é uma análise sistemática sobre o tema educação em Direitos Humanos para uma formação na cidadania disponibilizada no banco de dados Google Acadêmico, com vistas a orientar um projeto de pesquisa orientado à cidadania e direitos humanos na educação infantil. A revisão sistemática se deu em quatro passos: 1) delimitação do objetivo da pesquisa; 2) definição de termos ou palavras-chave; 3) seleção dos estudos encontrados em convergência com uma base de dados definida; 4) escolha de estudos fidedignos a responder a pergunta-problema: Como educar em direitos humanos e para uma cidadania global na Educação Infantil? Restaram dez artigos que serviram como base de discussão e apreensão de conceitos sobre o tema. Não foram encontrados indícios de que há uma especificidade a ser observada para o processo formativo de professores que atuam com crianças pequenas, mas é fundamental para a educação a valorização da dignidade e os princípios democráticos e o exercício da cidadania, que compreende direitos e deveres que encerram uma nova cultura que tenha como centro o ser humano.

Palavras-chave: Educação em direitos humanos. Educação infantil. Cidadania. Formação professores.

EDUCATION IN HUMAN RIGHTS AND FOR CITIZENSHIP THE PEDAGOGICAL EXPERIENCE OF TEACHER TRAINING IN CHILDREN EDUCATION: A SYSTEMATIC REVIEW OF THE LITERATURE

\section{ABSTRACT}

This paper is a systematic analysis on human rights education for citizenship education available in the Google Scholar database, a research program for citizenship and human rights in early childhood education. It was classified as four steps: 1 ) delimitation of the research objective; 2) definition of terms or keywords; 3) selection of studies found in convergence with a defined database; 4) choice of reliable studies and with answer to a problem question: how to educate in human rights and for a global citizenship in early childhood education? There were ten articles that served as a basis for discussion, apprehension of concepts on the topic. No indicators were found that there is a specificity to be a training instrument for teachers working with young children, but it is fundamental for education, the appreciation of dignity and democratic principles, the logo, the exercise of citizenship that includes rights and duties that have in view a new culture that has as its center the human being.

Keywords: Education in human rights. Child education. Citizenship. Teacher training.

\section{SUMÁRIO}

1 Introdução. 2 Metodologia. 3 Resultados da revisão sistemática. 4 Conclusão. 5 Referências.

Recebido em: 30/4/2019

Modificações requeridas em: 25/7/2019

Aceito em: 29/7/2019 


\section{Humanos e \\ Democracia}

\section{INTRODUÇÃO}

A Educação em Direitos Humanos (EDH) é, na atualidade, um dos mais importantes instrumentos dentre as formas de combate às violações de direitos humanos, posto que educa na tolerância, na valorização da dignidade e nos princípios democráticos. Sua inserção nos vários âmbitos do saber, porém, requer a compreensão do seu significado e da sua práxis. No campo da educação formal, é igualmente necessário estar atento às metodologias que lhe são compatíveis e às possibilidades de que ela possa permear os conteúdos de todas as disciplinas numa perspectiva interdisciplinar.

Neste sentido, a formação de educadores que estejam aptos a trabalhar a EDH é o primeiro passo para sua efetivação. Ela deve passar pelo aprendizado dos conteúdos específicos de direitos humanos, mas deve, especialmente, estar relacionada à coerência das ações e atitudes tomadas no dia a dia. Sem esta coerência o discurso fica desarticulado da prática e deslegitima o elemento central da EDH: a ética.

Por outro lado, também é preciso ter a consciência de que a formação é o estágio inicial, mas que o processo educativo em direitos humanos é contínuo e se consolidará ao longo da prática dos direitos humanos. A finalidade maior da EDH é a constituição de uma cultura de direitos humanos e, nesta perspectiva, está sempre em renovação. É a educação em direitos humanos que permite a afirmação de tais direitos e que prepara cidadãos e cidadãs conscientes de seu papel social no enfrentamento, não somente reconhecimento, contra as desigualdades e injustiças, e aborda as questões relacionadas a este processo de conscientização e construção do saber nesta área.

Como os professores educam em direitos humanos e para a cidadania global na Educação Infantil? Esta pergunta-problema desencadeou este trabalho, que centra seu foco na formação dos professores em direitos humanos a partir de uma perspectiva interdisciplinar.

\section{METODOLOGIA}

A proposta de revisão sistemática de Sampaio e Mancini (2007) foi utilizada. A revisão sistemática é uma forma de pesquisa que utiliza como fonte de dados a literatura sobre determinado temas. Esse tipo de investigação disponibiliza um resumo das evidências relacionadas a uma estratégia de intervenção específica, mediante a aplicação de métodos explícitos e sistematizados de busca, apreciação crítica e síntese da informação selecionada (SAMPAIO; MANCINI, 2007, p. 2), constituindo, assim, uma pesquisa em fontes secundárias.

Conforme as autoras, são quatro os passos propostos: 1) formulação clara e precisa do objetivo da pesquisa; 2) definição dos termos ou palavras-chave, assim como a base de dados; 3) seleção dos estudos encontrados em convergência com a pesquisa; 4) escolha de estudos fidedignos e com validade, 5) apresentação dos resultados.

O objetivo desta revisão sistemática foi identificar as concepções acerca da educação em direitos humanos e para a cidadania global por professores(as) da Educação Infantil presentes na produção acadêmica publicada na forma de artigos científicos, e discuti-las a partir do conhecimento dos documentos oficiais nacionais que orientam as práticas pedagógicas da educação em direitos humanos. 
Iniciou-se a busca pelos artigos na primeira quinzena de julho de 2018, tendo como base de dados o Google Acadêmico com a utilização dos descritores: Educação em Direitos Humanos, educação infantil, cidadania e professores educação infantil, sem indicação de qualquer recorte temporal. Esta busca resultou na identificação de 45 artigos, conforme o seguinte esquema:

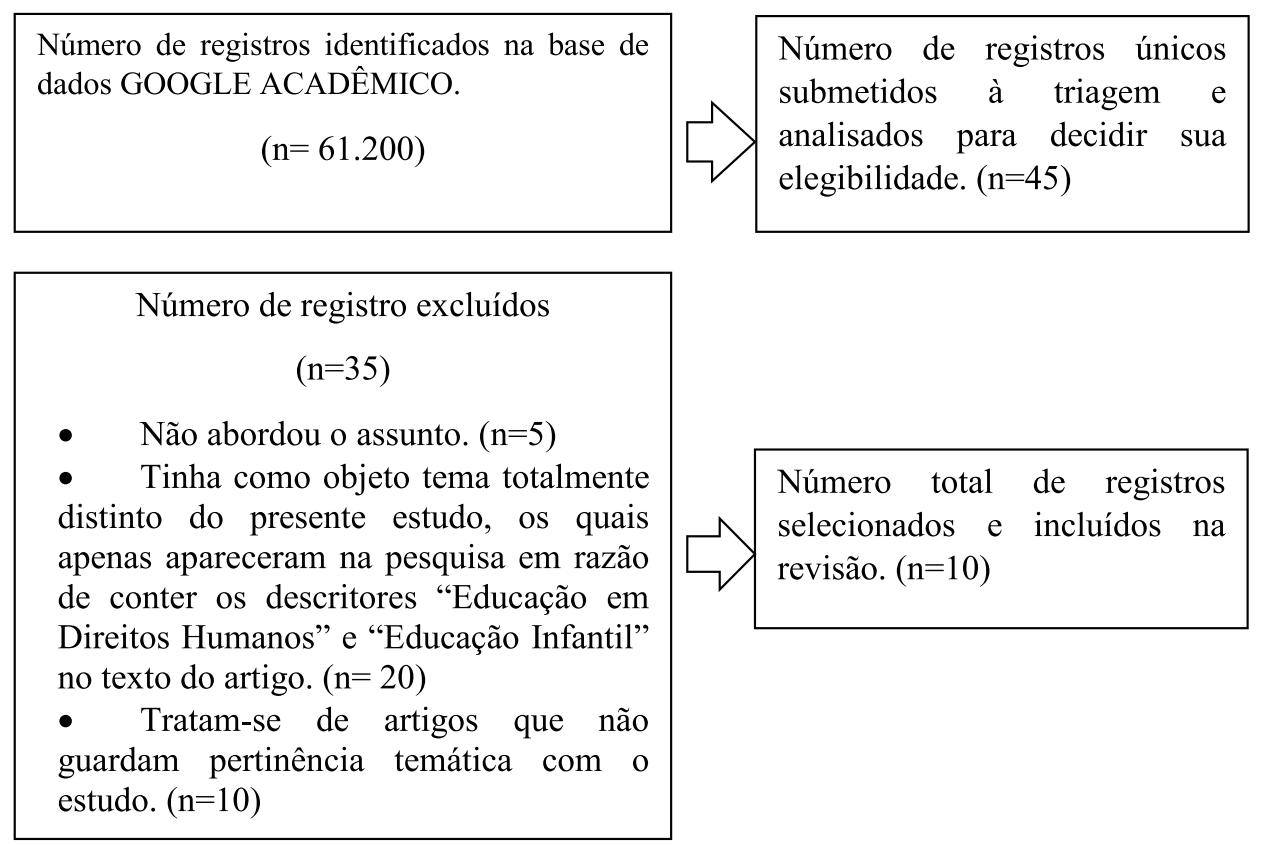

Os 45 artigos triados foram publicados entre os anos de 2004 e 2017. Estes artigos foram previamente analisados mediante a leitura das seções resumo, introdução e conclusão, o que resultou na exclusão de 35 artigos, pois não apresentavam convergência para responder à pergunta-problema da pesquisa. Este percurso metodológico resultou em dez artigos fichados e analisados, os quais dão origem a esta revisão sistemática.

\section{RESULTADOS DA REVISÃO SISTEMÁTICA}

Após análise dos conteúdos completos dos dez artigos selecionados, foi possível categorizar os tópicos-temas em quatro campos de discussão: 1) o que são Direitos Humanos; 2) o que se entende por cidadania; 3) o que caracteriza a Educação em Direitos Humanos; 4) a formação dos professores. Os achados são apresentados a seguir.

Direitos Humanos é uma forma abreviada de se referir a um conjunto de exigências e enunciados jurídicos que são superiores aos demais direitos. Superiores porque anteriores ao Estado, porque não são meras concessões da sociedade política, mas nascem com o homem, fazem parte da própria natureza humana e da dignidade que lhe é inerente. Sem eles o homem não é capaz de existir, de se desenvolver e participar plenamente do mundo. São universais, porque exigíveis de qualquer autoridade política, em qualquer lugar. Eles representam as condições mínimas necessárias para uma vida digna. Estes direitos possuem algumas características que se identificam com sua natureza, pois fazem parte da própria essência e os diferem de outros direitos. 


\section{Humanos e}

Democracia

Para Callo (1977, p. 11-12), as características supramencionadas são as seguintes: a) são inatos ou congênitos, porque se nasce com eles, como atributo inerente a todo ser humano, diferente de outros direitos que se vão adquirindo durante toda a vida; b) são universais, pois se estendem a todo gênero humano, em todo tempo e lugar; c) são absolutos, porque seu respeito se pode exigir de qualquer pessoa, autoridade ou comunidade inteira, diferente dos direitos relativos, como os emanados das relações contratuais, que somente podem ser exigidos de quem contratou a obrigação correspondente; d) são necessários, sua existência não deriva de um fato contingente (ou seja, que pode ser ou não), mas constitui uma necessidade ontológica derivada da própria natureza da pessoa humana; e) são inalienáveis, pois pertencem à essência do ser humano de forma indissociável, assim não se pode renunciar, transferir ou transmitir-se, sob nenhum título, como ocorre com os demais direitos que são objetos de transações jurídicas; f) são invioláveis, nenhuma pessoa ou autoridade pode atentar legitimamente contra eles (sem prejuízo das justas limitações que podem se impor a seu exercício, de acordo com as exigências do bem comum da sociedade); g) são imprescritíveis, não caducam nem se perdem com o decurso do tempo, ainda que um grupo ou uma pessoa determinada se veja materialmente impedida de exercê-los devido a insuperáveis circunstâncias de fato.

Este é um processo sem fim porque, segundo Bobbio,

Ainda que fossem necessários, os direitos não nascem todos de uma vez. Nascem quando devem ou podem nascer. Nascem quando o aumento do poder do homem - que acompanha inevitavelmente o progresso técnico, isto é, o progresso da capacidade do homem de dominar a natureza e os outros homens - ou cria novas ameaças à liberdade do indivíduo ou permite novos remédios para as suas indigências: ameaças que são enfrentadas através de demandas de limitações do poder (1992, p. 6).

Pode-se verificar que os direitos humanos não são uma construção teórica, mas uma resposta sociológica, histórica e geograficamente referenciáveis. São, todavia, direitos inerentes a todos os seres humanos, independentemente de raça, sexo, nacionalidade, etnia, idioma, religião ou qualquer outra condição. A perspectiva apresentada na revisão conjectura que os direitos humanos se arranjam a partir das ações e das relações humanas, nas suas diversidades.

Registre-se especialmente que a adesão pelo Estado, ou seja, Direito Internacional dos Direitos Humanos, institui as obrigações dos governos de atuarem de certo modo ou não praticarem determinados atos, a fim de proteger ou promover os direitos humanos bem como as liberdades individuais ou de grupos específicos.

Assim, a partir da Declaração Universal dos Direitos Humanos, alguns assuntos passaram a ser considerados universais para quase todos os seres humanos, tais como direito à saúde, educação, liberdade para expressar-se, direito a ter respeitada a sua fé, direito de se deslocar livremente em tempo de paz, receber herança, entre outros.

Estes direitos exigem ações dos indivíduos e deveres em relação ao Estado, tais como: escolher os governantes, cumprir leis, educar e proteger os demais humanos, a natureza e o patrimônio público. Logo, viver os direitos e praticar os deveres está na origem da construção de cidadania. 
Neste estudo de revisão, a aplicação do conceito de cidadania é imprescindível para que haja uma melhor organização social. Exercer a cidadania é ter consciência de seus direitos e obrigações, garantindo que estes sejam postos em prática.

Define-se, de uma maneira geral, cidadania como a qualidade ou o direito do cidadão, e cidadão como o indivíduo no gozo de direitos civis e políticos de um Estado. Assim também é o entendimento de Silva (1997, p. 305), de que a "cidadania qualifica os participantes da vida do Estado, é atributo das pessoas integradas na sociedade estatal, atributo político decorrente do direito de participar no governo e direito de ser ouvido pela representação política". Como se verifica, a cidadania está muito próxima do nacionalismo, até porque a forma de se adquirir cidadania é pela nacionalidade, que é um conceito jurídico, enquanto aquele seria um conceito político.

Cidadania é o direito a ter uma ideia e poder expressá-la. Não há como conceituar cidadania sem se considerar o contexto social a que se está referindo e, com isso, a mesma adquire características próprias que se diferenciam conforme o tempo, o lugar e as condições socioeconômicas. Para Dulce (2000), isso ocorre porque o conceito de cidadania não corresponde a uma categoria natural; trata-se de uma construção metafórica que surge como consequência de processos históricos de negociação, mediante a qual se estabelece um duplo vínculo de caráter abstrato entre os "cidadãos" e sua organização jurídico-política: de um lado o Estado protege seus cidadãos, de outro, os cidadãos participam da criação e da direção da atividade jurídica e política do Estado.

Então, cidadão é o indivíduo que tem liberdade e, possuindo-a, age ativamente na configuração do futuro de sua sociedade por meio da participação. Como se observa, o termo encerra certa ambiguidade, pois supõe um conjunto de direitos e, ao mesmo tempo, de deveres em relação à sociedade. Embora esteja ligado muito estreitamente à noção de direito, especialmente na dimensão política, é a cidadania que permite que as pessoas intervenham na direção das questões do Estado, de forma direta ou indireta, na administração pública.

As pessoas vão se tornando cidadãs também pela atividade educativa, pela vida em sociedade; por isso a cidadania é processo individual assim como na dimensão sociológica, pois vai se efetivando na mesma medida que direitos são conquistados e garantidos; por isso é um processo em contínua construção, quiçá, aperfeiçoamento.

Em resumo, a origem da Cidadania está nos Direitos Humanos, mas é mais restrita. Então, se os direitos de cidadania e Direitos Humanos são distintos, haverá diferenças também na educação dirigida.

Educar para a cidadania é despertar no indivíduo a consciência de seus direitos e deveres com sua comunidade política, muito mais para saber exigir e opor-se a ações totalitárias do Estado e seus órgãos e deles participar politicamente. É a exaltação dos feitos e das glórias do seu povo; é uma educação cívica.

A educação em direitos humanos, por sua vez, é um campo recente tanto no contexto brasileiro quanto no latino-americano, apesar de vários documentos internacionais já tratarem sobre a necessidade de sua execução. Educar para os direitos humanos é ensinar a respeitar os direitos dos demais; é educar para a paz, para a tolerância, para o amor, é ensinar a doar-se pelo bem comum. 


\section{Humanos e}

Democracia

O Relatório do Instituto Interamericano de Direitos Humanos (2012) sobre o tema, mostra que, desde a Declaração Universal de Direitos Humanos (1948) e, mais especificamente, no Protocolo Adicional à Convenção Interamericana sobre Direitos Humanos em matéria de Direitos Sociais, Econômicos e Culturais, o direito à educação em direitos humanos faz parte do direito à educação (IIDH, 2000, p. 6).

Nesta perspectiva, identifica-se uma relação intrínseca entre ambas. A educação é o caminho para qualquer mudança social que se deseje realizar dentro de um processo democrático. A educação em direitos humanos, por sua vez, é o que possibilita sensibilizar e conscientizar as pessoas para a importância do respeito ao ser humano, apresentando-se, na atualidade, como uma ferramenta fundamental na construção da formação cidadã, assim como na afirmação de tais direitos. Magendzo (1994, p. 23) a define como a prática educativa que se funda no reconhecimento, na defesa e no respeito e promoção dos direitos humanos e que tem por objeto desenvolver nos indivíduos e nos povos suas máximas capacidades como sujeito de direitos e proporcionar as ferramentas e elementos para fazê-los efetivos.

A finalidade maior da EDH, portanto, é a de atuar na formação da pessoa em todas as suas dimensões, a fim de contribuir ao desenvolvimento de sua condição de cidadão e cidadã, ativos na ação por seus direitos, no cumprimento de seus deveres e na fomentação de sua humanidade. Dessa forma, uma pessoa que goza de uma educação neste âmbito é capaz de atuar ante as injustiças e desigualdades, reconhecendo-se como sujeito autônomo e, ademais, reconhecendo o outro com iguais direitos e preceitos de diversidade e tolerância, valorizando, assim, a convivência harmoniosa, o respeito mútuo e a solidariedade. É igualmente por meio dessa educação que se pode começar a mudar as percepções sociais radicais, discriminatórias e violentas, na maioria das vezes, legitimadoras das violações de direitos humanos, e reconstruir as crenças e valores sociais fundamentados no respeito ao ser humano e em conformidade com os preceitos democráticos e as regras do Estado de Direito (TAVARES, 2007).

A relevância da educação em direitos humanos pode ser mensurada por intermédio dos documentos da ONU sobre o tema, como o Decênio das Nações Unidas para a Educação na Esfera dos Direitos Humanos (1995-2004) ou o Programa Mundial para a Educação em Direitos Humanos, aprovado no final de 2004. Este Programa está estruturado em fases sucessivas, com sua primeira etapa guiada por um plano de ação para 2005-2007. O Programa estabelece que a EDH deva fortalecer o respeito aos direitos humanos e às liberdades fundamentais; desenvolver plenamente a personalidade humana e o sentido da dignidade do ser humano; promover a compreensão, a tolerância e a igualdade; facilitar a participação efetiva de todos numa sociedade livre e democrática, na qual impere o Estado de Direito; fomentar e manter a paz e promover o desenvolvimento sustentável centrado nas pessoas e na justiça social (NACIONES UNIDAS, 2007, p. 4-5).

Ainda de acordo com o referido Programa, este tipo de educação deve contribuir para: a) criar uma cultura universal dos direitos humanos; b) exercitar o respeito, tolerância, promoção e valorização da diversidade religiosa, de gênero, de orientação sexual e cultural e a amizade entre as nações, povos indígenas e grupos étnico-raciais; c) possibilitar a todas as pessoas terem acesso à participação efetiva em uma sociedade livre (NACIONES UNIDAS, 2007, p. 5). 
Anteriormente à Conferência Mundial de Direitos Humanos, por meio da Declaração de Viena, de 1993, já tinha indicado sua importância, ao considerar que "a educação, a capacitação e a informação pública em direitos humanos são indispensáveis para estabelecer e promover relações estáveis e harmoniosas entre as comunidades e para fomentar a compreensão mútua, a tolerância e a paz" (NACIONES UNIDAS, 2007, artigo 78, p. 20). No Brasil, o campo normativo relacionado aos direitos humanos e a educação nesta área se incorporam nos seguintes documentos: Constituição Federal (1988), Lei de Diretrizes e Bases da Educação (1996), Parâmetros Curriculares da Educação (a partir de 1997), Programa Nacional de Direitos Humanos (na sua primeira versão, em 1996 e segunda versão, em 2002) e Plano Nacional de Educação em Direitos Humanos (também com duas versões, 2003 e 2006). Estes documentos estabelecem as diretrizes à formação cidadã, tendo como cinco grandes eixos de atuação: Educação Básica; Educação Superior; Educação Não Formal; Educação dos Profissionais dos Sistemas de Justiça e Segurança Pública; Educação e Mídia.

Direciona, ainda, ações para a concretização do processo sistemático e multidimensional que orienta a formação do sujeito de direitos, articulando as seguintes dimensões:

- Apreensão de conhecimentos historicamente construídos sobre direitos humanos e a sua relação com os contextos internacional, nacional e local;

- Afirmação de valores, atitudes e práticas sociais que expressem a cultura dos direitos humanos em todos os espaços da sociedade;

- Formação de uma consciência cidadã capaz de se fazer presente em níveis cognitivo, social, ético e político;

- Desenvolvimento de processos metodológicos participativos e de construção coletiva, utilizando linguagens e materiais didáticos contextualizados;

- Fortalecimento de práticas individuais e sociais que gerem ações e instrumentos em favor da promoção, da proteção e da defesa dos direitos humanos, bem como da reparação das violações (BRASIL, 2010, p. 11).

A educação em direitos humanos, além de todo processo de formação em seus conteúdos, pretende a socialização dos valores e princípios que lhe são intrínsecos, com o fim de construir e consolidar uma cultura de direitos humanos. Neste caminho, a dita socialização busca envolver todas as pessoas na vivência e no respeito a tais direitos. Esse objetivo vem demarcado no último documento da ONU nesta área, em que a EDH é sinônimo do "conjunto das atividades de capacitação e difusão orientadas a criar uma cultura universal na esfera dos direitos humanos" (NACIONES UNIDAS, 2007, p. 4). A importância de estabelecer os direitos humanos como uma cultura na sociedade brasileira decorre da estrutura social existente, em que os fortes traços do colonialismo e da escravidão, presentes durante vários séculos, ainda encontram ressonância e alimentam o autoritarismo, a discriminação, a exclusão e o preconceito atuais. Somente quando os direitos humanos passarem a fazer parte do cotidiano de todas as pessoas e se constituam de fato numa cultura, será possível a generalização e a perpetuação de crenças, valores, conhecimentos, práticas e atitudes que priorizem o ser humano.

É por isso que a EDH deve estar orientada para a plena realização da pessoa, o sentido da dignidade e o fortalecimento dos direitos e liberdades fundamentais, assim como para a promoção da justiça e da paz. Com estes elementos, é possível nortear uma vivência democrática e cidadã de respeito integral ao ser humano. 


\section{Democracia}

Humanos e

A formação do professor em direitos humanos depende tanto de uma prática pedagógica condizente com o respeito ao ser humano quanto de uma educação que privilegie a interdisciplinaridade e a multidimensionalidade que envolve a temática. Esses aspectos representam uma nova postura diante do conhecimento, possibilitando uma ação educativa capaz de ampliar as capacidades, desenvolver a consciência crítica diante da informação e priorizar a interação e participação de forma democrática. O foco, portanto, valoriza o que é construído e não simplesmente transmitido.

O professor em direitos humanos tem diante de si uma responsabilidade imensa. Primeiro, de educar-se a si mesmo e, depois, de educar aos demais na tolerância, no respeito, na compreensão da diferença. Segundo, de atuar democraticamente e com persistência para que o compromisso com as transformações sociais, necessárias para reverter as injustiças e desigualdades, possa chegar a ser o horizonte de todos (TROMBETTA; LUFT, 2016).

A metodologia da educação em direitos humanos envolve três pontos essenciais: primeiro, educação permanente, continuada e global; segundo, ser voltada para a mudança cultural; terceiro, ser pautada em valores para superar a mera transmissão de conhecimentos (BENEVIDES, 2007). Na estruturação dessa metodologia utiliza-se oficinas de direitos humanos (CANDAU, 1996), as quais buscam a humanização, com o foco central de trabalhar a atitude crítica e ética, mas também a sensibilidade e o respeito ao ser humano, pois as oficinas são uma metodologia didática indicada para quando o docente deseja a formação coletiva. A oficina promove a construção de saberes horizontalmente.

Assim, o conceito de oficinas aplicado à educação refere-se ao lugar onde se aprende fazendo junto com os outros. O processo pedagógico precisa promover a construção de relações justas, democráticas e do respeito ao pluralismo cultural. Nesse sentido, é certo afirmarmos que as oficinas em direitos humanos consolidam uma metodologia que reafirma a ação pedagógica como exercício contínuo do diálogo, entre educadores e educandos, em busca de emancipação, portanto é práxis.

Esta orientação é universal, aplicando-se a todas as dimensões: educação básica, superior, não escolar e, por conseguinte, à educação Infantil.

A formação dos professores em direitos humanos deve privilegiar as metodologias ativas e participativas de forma a envolver e despertar o interesse, sem esquecer o sensibilizar, indignar-se, atuar de forma comprometida, para que o professor em direitos humanos se articule com a historicidade na qual está inserido. Em síntese, a metodologia para o desenvolvimento da Educação em Direitos Humanos, na educação infantil, requer a seleção e organização dos conteúdos e atividades, materiais e recursos didáticos, que sejam condizentes com a finalidade de um processo educativo em direitos humanos em âmbito do desenvolvimento das crianças pequenas. O foco central é fazer os futuros professores entender que a proposta deve ser inspiradora de novas práxis, e não de ações vazias de sentido e significado para eles e seus alunos.

O primeiro passo neste sentido é pensar na função da escola nesta missão. Assim sendo, é fundamental redefinir seu perfil e considerar o fato de que a organização escolar não é neutra. De acordo com Silva (1997, p. 16), "é necessária a construção de um projeto pedagógico democrático e participativo, onde a formação do sujeito possa ser assumida coletivamente". A autora igualmente afirma que um projeto de escola que tenha como compromisso a formação em direitos humanos, deve considerar os seguintes elementos: a educação formal 
é condição essencial à formação da cidadania e tem na escola seu lugar privilegiado; a escola tem de cumprir, de fato, seu papel e função social, enquanto espaço de elaboração e socialização do conhecimento; a educação em direitos humanos deve ser um projeto global da escola; o desenvolvimento de um processo de conscientização dos direitos e deveres deve ser contínuo e permanente (SILVA, 1997, p. 220-221).

Conforme análise de Candau (1996, p. 14-15), uma proposta metodológica inspirada nesta perspectiva entende que "a escola deveria exercer um papel de humanização a partir da socialização e da construção de conhecimentos e de valores necessários à conquista do exercício pleno da cidadania". Como a EDH se dá no dia a dia, nas diversas situações e relações cotidianas, é preciso haver um compromisso com os direitos humanos e o desenvolvimento de uma prática pedagógica democrática.

Da mesma forma, é necessário que o professor não seja um mero transmissor dos conteúdos formais e sim que: a) acredite no que faz, pois, sem a convicção de que o respeito aos direitos humanos é fundamental para todos, não é possível despertar os mesmos sentimentos nos demais; b) eduque com o exemplo, porque de nada adianta ter um discurso desconectado da prática ou ser incoerente, exigindo aos demais determinadas atitudes que a própria pessoa não cumpre; c) desenvolva uma consciência crítica com relação à realidade e um compromisso com as transformações sociais, posto que o propósito deste tipo de educação é formar sujeitos ativos que se empenham pelo respeito aos direitos de todos.

\section{CONCLUSÃO}

O estudo demonstrou que educar em direitos humanos significa ter a vida cotidiana como referência contínua. É um aprendizado que não ocorre de forma pontual ou isolada, mas que, sistematicamente, faz parte da ação educacional. Por isso, é importante a elaboração de abordagens condizentes com este tipo de educação que possam contribuir para seu exercício. $O$ ponto de partida deve ser o que articule os saberes docentes em direitos humanos e que oportunize aos educadores uma ampla gama de opções, de observações, de análises, de descobertas. É preciso consolidar o aprendizado pela vivência e fazer do exercício cotidiano da cidadania uma prioridade para a escola.

Como uma das finalidades da EDH é despertar a responsabilidade com a defesa do respeito ao ser humano, é fundamental sensibilizar e fomentar o compromisso. A formação nesta perspectiva deve propiciar ao educador o conhecimento e a experiência em direitos humanos, mas, sobretudo, oportunizar a socialização dos preceitos e valores relacionados a essa área.

O enfoque deve passar pela abordagem que permita estabelecer um diálogo com os demais conteúdos e níveis do conhecimento. Uma formação em EDH que não dê preferência a esta questão, será incapaz de romper com as representações e percepções prévias e proporcionar aos educadores outro olhar sobre o qual assentar sua prática. É fundamental educar na tolerância, na valorização da dignidade e nos princípios democráticos, construindo uma nova cultura que tenha como centro o ser humano.

Este é um desafio no qual a contribuição dos educadores em direitos humanos é inestimável. Por isso, sua própria formação deve, desde o princípio, corresponder a estes valores que se pretende socializar. Igualmente, é preciso não perder a perspectiva da coerência entre 
o discurso e as atitudes tomadas no dia a dia. O horizonte será sempre o mesmo: o respeito ao ser humano e a sua dignidade. A construção desse horizonte, porém, depende do grau de envolvimento e disposição que pode haver em cada um.

Oportunizar, portanto, a formação do educador em direitos humanos, em consonância com os valores que the são intrínsecos e desde uma abordagem interdisciplinar e multidimensional, é, na atualidade, um passo a mais na construção de uma cultura de direitos humanos.

A educação em Direitos Humanos já tem caminho construído no Brasil e em todo o continente latino-americano. No momento atual, o desafio fundamental é avançar em sintonia com seu motivo fundante, qual seja: seu compromisso histórico com uma mudança estrutural que viabilize uma sociedade inclusiva e a centralidade dos setores populares nesta busca. Estas opções constituíram - e continuam sendo - a fonte de sua energia ética e política.

Conclui-se ter esta revisão sistemática um caráter introdutório, tendo em vista suscitar questões para o debate pedagógico no momento atual da educação infantil. Não foram, todavia, encontradas especificidades para este nível de ensino; ao contrário, o conjunto de orientação aplica-se a todos os grandes eixos de atuação: Educação Básica, Educação Superior, Educação Não Formal, Educação dos Profissionais dos Sistemas de Justiça e Segurança Pública e, por conseguinte, Educação Infantil.

Enfim, os direitos humanos apresentam-se como uma utopia a promover e plasmar diferentes níveis e espaços da sociedade. Como tais, estão como um marco ético-político que serve de crítica e orientação (real e simbólica) em relação às diferentes práticas sociais (jurídica, econômica, educativa, etc.) no enfrentamento nunca acabado por uma ordem social mais justa e livre. Neste sentido, são vistos como paradigmáticos, isto é, como modelo e/ou critério exemplar a partir do qual é possível ler nossa história e nosso futuro como povo, pois a finalidade maior da EDH é a constituição de uma cultura de direitos humanos e, nesta perspectiva, estará sempre em renovação.

Esta revisão sistemática proporcionou um método de trabalho com os artigos de interesse da pesquisa, que auxiliou na sistematização do tema a partir dos artigos triados pelos descritores educação em direitos humanos, educação infantil, cidadania; professores educação infantil. A importância da temática, contudo, proporcionou às pesquisadoras um contato ampliado com outras discussões realizadas no meio acadêmico; razão pela qual se verificou uma oportunidade de continuação de estudos a partir da análise das sentenças da Corte Interamericana de Direitos Humanos, nas quais os Estados-parte foram obrigados a promover educação em direitos humanos.

\section{REFERÊNCIAS}

BARCELLOS, Carlos Alberto. Fundamentos sociológicos da educação para a cidadania. In: BARCELLOS, Carlos Alberto (org.). Educando para a cidadania - os Direitos Humanos no currículo escolar. São Paulo: Seção Brasileira da Anistia Internacional; Centro de Assessoramento a Programas de Educação para a Cidadania, 1992. p. 74-95. BENEVIDES, Maria Victoria. A cidadania ativa. São Paulo: Ática, 1991.

BOBBIO, N. A era dos direitos. Rio de Janeiro: Campus, 1992.

BOBBIO, N. O futuro da democracia: uma defesa das regras do jogo. Rio de Janeiro: Paz \& Terra, 1986.

BRASIL. Secretaria de Direitos Humanos da Presidência da República. Programa Nacional de Direitos Humanos - PNDH 3. 2010. Disponível em: http://www. pndh3.sdh.gov.br/public/downloads/PNDH-3.pdf. Acesso em: 26 jul. 2019. 
BRASIL. Presidência da República; Secretaria Especial dos Direitos Humanos. Plano Nacional de Educação em Direitos Humanos - PNDH. Brasília: Comitê Nacional de Educação em Direitos Humanos; Ministério da Educação; Ministério da Justiça; Unesco, 2006a.

BRASIL. Constituição da República Federativa do Brasil. Brasília, DF: Senado, 1988.BRASIL. Comitê Nacional de Educação em Direitos Humanos. Plano Nacional de Educação em Direitos Humanos. Brasília, DF: Secretaria Especial dos Direitos Humanos; MEC, 2006b.

BRASIL. Constituição da República Federativa do Brasil de 05 de outubro de 1988. Constituição Federal. 8. ed. Porto Alegre: Verbo Jurídico, 2007.BRASIL. Declaração e Programa de ação da Conferência Mundial sobre os Direitos Humanos. Viena, 1993. Disponível em: https://www.oas.org/dil/port/1993\%20Declara\%C3\%A7\%C3\%A30\%20e\%20Programa\%20de\%20Ac\%C3\%A7\%C3\%A30\%20adoptado\%20pela\%20Confer\%C3\%AAncia\%20 Mundial\%20de\%20Viena\%20sobre\%20Direitos\%20Humanos\%20em\%20junho\%20de\%201993.pdf. Acesso em: 26 jul. 2019.CALLO, Jorge Iván Hübner. Panorama de los Derechos Humanos. Buenos Aires: Editora da UBA, 1977. CANDAU, V. M. F. Educação em direitos humanos e formação de professores/as. In: SCAVINO, S.; CANDAU, V. M. F. (org.). Educação em direitos humanos: temas, questões e propostas. Petrópolis: DP et alii, 2008.

CANDAU, Vera et al. Tecendo a cidadania: oficinas pedagógicas de direitos humanos. Petrópolis: Vozes, 1996.

CHAUÍ, Marilena. Cultura e democracia. São Paulo: Moderna, 1984.

DECLARAÇÃO INTERNACIONAL DOS DIREITOS HUMANOS. Organização das Nações Unidas (ONU). 1948.

DULCE, Maria José Fariñas. Globalización, ciudadanía y Derechos Humanos. Madrid: Dykinson, 2000.

IIDH. Instituto Interamericano de Derechos Humanos. Informe Interamericano de la Educación en Derechos Humanos: un estudio en 19 países. Parte I - desarrollo normativo. San José: IIDH, 2002.

IIDH. Instituto Interamericano de Derechos Humanos. Relatório interamericano de educação em direitos humanos: um estudo em 19 países, desenvolvimento nas políticas de convivência e segurança escolar com enfoque de direitos. San José, C.R.: Instituto Interamericano de Derechos Humanos - IIDH, 2012. Disponível em: https:// www.iidh.ed.cr/IIDH/media/1526/x-informe-portugues-2011.pdf. Acesso em: 26 jul. 2019.

LEI de Diretrizes e Bases da Educação Nacional (9.394/96). 1996a. Disponível em: http://www.planalto.gov.br/ CCIVIL_03/LEIS/L9394.htm. Acesso em: 9 jul. 2018.

LEI de Diretrizes e Bases da Educação Nacional (LDB). 20.12.1996. 1996b.Disponível em: http://portal.mec.gov. br/seesp/arquivos/pdf/lei9394_Idbn1.pdf. Acesso em: 9 jul. 2018.

MAGENDZO, A. (org.) Educación en Derechos Humanos: apuntes para una nueva práctica. Chile: Corporación Nacional de Reparación y Reconciliación e PIIE, 1994.

NACIONES UNIDAS. Projecto revisado del plan de acción para la primera etapa (2005-2007) del Programa Mundial para la Educacción en Derechos Humanos. Disponível em: http//www.lpp-vexj.net/ol ped/dcocumentos/0827.pdf. Acesso em: 23 ago. 2007.

NAÇÕES UNIDAS NO BRASIL. Relatório do Desenvolvimento Humano 2003. Disponível em: http://www.br.undp. org/content/brazil/pt/home/library/idh/relatorios-de-desenvolvimento-humano/relatorio-do-desenvolvimento-humano-20003.html. Acesso em: 9 jul. 2018.

ONU; UNESCO. Declaración de México sobre Educación en Derechos Humanos en América Latina y el Caribe. Ciudad de México, dic. 2001.

PEIRANO, Mariza G. Sem lenço e sem documento. Reflexões sobre a cidadania no Brasil. Sociedade e Estado. Brasília: UnB, 1986. p. 85-117.

PLANO Nacional de Educação. Disponível em: http://portal.mec.gov.br/arquivos/pdf/pne.pdf. Acesso em: 9 jul. 2018. SAMPAIO, R. F.; MANCINI, M. C. Estudos de Revisão Sistemática: um guia para síntese criteriosa da evidência científica. Revista Brasileira de Fisioterapia, v. 11, n. 1, p. 83-89, 2007. Disponível em: http://www.scielo.br/pdf/ rbfis/v11n1/12.pdf. Acesso em: 10 set. 2019.

SILVA, Aida. Educação para a cidadania: solução ou sonho impossível. In: LERNER, Julio (org.). Cidadania, verso e reverso. São Paulo: Imprensa Oficial do Estado, 1997. p. 215-222.

SIME, L. Educación, Persona y Proyecto Histórico. In: MAGENDZO, A. (org.). Educación en Derechos Humanos: apuntes para una nueva práctica. Chile: Corporación Nacional de Reparación y Reconciliación e PIIE, 1994.

TAVARES, Celma. Educar em direitos humanos, o desafio da formação dos educadores numa perspectiva interdisciplinar. Educação em Direitos Humanos: fundamentos teóricos metodológicos. João Pessoa: Editora Universitária UFPB, 2007. p. 487-503. Disponível em: http://www.cchla.ufpb.br/ncdh/wp-content/uploads/2014/07/ merged.compressed.pdf. Acesso em: 9 jul. 2018.

TROMBETTA, Sérgio; LUFT, Hedi Maria. Práticas pedagógicas na dimensão dos direitos humanos. In: COLÓQUIO INTERNACIONAL PAULO FREIRE - CAMPUS UNIVERSIDADE FEDERAL DE PERNAMBUCO, 9., 2016, Recife. Anais [...]. Recife: Ufpe, 2016. p. 1-12. V. 1. Disponível em: www.dhnet.org.br/dados/livros/edh/br/fundamentos/29_ cap_3_artigo_07.pdf. Acesso em: 26 jul. 2019.

UNESCO. Fórum Mundial sobre Educação de Dakar. Disponível em: http://unesdoc. unesco.org/ images/0012/001275/127509porb.pdf. Acesso em: 9 jul. 2018. 